\title{
LITERATURA, DEPRESIÓN Y EXÉGESIS EN LA OBRA DE SAN JUAN DE LA CRUZ. CONTEXTUALIZACIÓN LITERARIA DE UN PROBLEMA PSIQUIÁTRICO.
}

\author{
José Manuel TRABADO CABADO \\ Universidad de León
}

La reciente aparición del libro de Javier Alvarez ${ }^{1}$ merece una reflexión sobre el tipo de relaciones que el texto literario, en cuanto que vehiculo catárquico, pueda establecer con las explicaciones que tanto la psicologia como la psquiatría proporcionan a propósito de sus descripciones de estados psicopatológicos. Se impone además la necesidad, necesidad que ha guiado la escritura de estas notas, de plantear el problema desde una perspectiva un tanto diferente a la elegida por Javier Álvarez. La diferencia estriba en otorgar un mayor protagonismo al hecho literario para ubicarlo dentro de las coordenadas poéticas que definían el proceso creador en la época de San Juan de la Cruz.

No es necesario advertir que psicología y literatura están unidas desde el momento en que todo escritor en el proceso de escritura ensaya itinerarios imposibles con el afán de vivir otras vidas que le son negadas. Hermosas son las palabras de Castilla del Pino cuando afirma: "Cualesquiera que sean los otros cometidos propuestos, hay algo consustancial con el autor: la necesidad que ha sentido de expulsar fragmentos de sí mismo convertidos en personajes de ficción, es decir, en fantasmas» ${ }^{2}$. Sin embargo, el estudio de estos fantasmas hubo de esperar un tiempo hasta que mereciera la atención de algunos sectores de la Teoría de la Literatura. Pasados ya los años en los que el estructuralismo marcaba las directrices a seguir en la metodología de los estudios literarios, se observa, precisamente, la pertinencia de ir más allá de los limítes estáticos y estrictos que marcaba el texto. Fue al transcender estos límites cuando surgió la oportunidad de rescatar los polos de la comunicación literaria: autor y lector. Ln preocupación por éste -me refiero al lector- tuvo un desarrollo paralelo en algunos teóricos de la Universidad de Constanza, que seguían el camino marcado por la hermenéutica (se llamó a este movimiento «Estética de la Recepción»), y en el marco de las teorias semióticas dentro de las cuales ha desarrollado sus estudios, entre otros, Umberto Eco ${ }^{3}$. También Eco desarrolla la noción del autor modelo que, al igual que el lector modelo -muy cercano al lector implícito de los teóricos de la recepción- viene definido en términos de

${ }^{3}$ Mistica y depresión: San Juan de la Cruz, Madrid, Trotta, 1997

2 "Literatura y ficción", en Temas. Hombre, cultura, sociedad, Barcelona, Ediciones Peninsula. 1989. pägs. 161-162 (paig. 162).

${ }^{3}$ Véase Umberto Eco, Los límites de la interprelación, Barcelona, Lumen, 1992. especialmente el capítulo I «Intentio lectoris. Apuntes sobre la semiótica de la recepciơn», págs. 21-46. 
estrategias textuales destinadas a recabar la cooperación del lector, entendido ya como persona empírica, para lograr el pleno funcionamiento del texto.

Sin embargo, otras escuelas prestaron su interés por la figura del autor desde otros puntos de vista. Me reliero a aquellos que practican e] método de la Psicocrítica ${ }^{4}$. A diferencia de los anteriores, la presencia del autor en su texto no hace alusión a una estrategia textual sino que, en la relación autor-obra, el texto actúa como vehículo donde se plasman las obsesiones de su creador. detectables por la frecuencia de uso de determinadas imágenes. Ni que decir tiene que estos desarrollos se basan, sobre todo, en las teorías de Freud ${ }^{5}$.

En estas coordenadas hay que situar la obra de Javier Alvarez sobre S. Juan y la depresión. Si bien es cierto que nada se dice al respecto de los presupuestos adoptados en su estudio, quizís debido a que su entrada al problema se realiza desde el terreno de la psiquiatría, su método presenta numerosos puntos de contacto con el utilizado por los integrantes de la escuela de la psicocrítica, ya que se intenta establecer un puente entre autor y texto desde un punto de vista psicológico y no textual tal y como hacian los teóricos de la recepción o los semiólogos.

No obstante lo dicho, la relación entre los procesos psicopatológicos que estudian tanto la psicologia como la psiquiatría y la literatura no es un hecho reciente. Reciente es sólo su sistematización desde las filas de los estudios literarios; como siempre, la préctica pone de manifiesto hechos mucho antes de que surja una reflexión teórica sobre el asunto. Qué duda cabe que ciencias como las anteriormente indicadas aprestan su instrumental para permitir adentrarnos en la sentina emocional en donde bulle aquello que resulta irreductible en el personaje y, en ocasiones aunque no siempre, en el creador. Significativo podria ser el inicio del capítulo sexto del Viaje del Parnaso que Cervantes publicó en 1614:
De una de las tres causas los ensueños se causan (o los sueños, que este nombre les dan los que del bien hablar son dueños): primera, de las cosas de que el hombre trata más de ordinario; la segunda, quiere la medicina que se nombre del humor que en nosotros más abunda; toca en revelaciones la tercera, que en nuestro bien más que las dos redunda.

\footnotetext{
4 Véase el trabajo de Anne Clancier, Psicoanálisis, literatura, critica, Madrid, Cútedra, 1979

${ }^{3}$ De obligada consulta san los trabajos de Carlos Castilla del Pino. Entre ellos, por ejemplo, puede leerse el repaso que haca de las aportaciones de la teoria psicoanalítica aplicada a la literatura en «El psicoanálisis, la hermenéutica del lenguaje y el universo literarion, en Teoría de la crítica literaria, ed. Pedro Aullön de llaro, Madrid, Trotta, 1994, pägs. 297-386. A ello puede añadirse Isabel Paraiso, Psicoanálisis de la Experien. cia literaria, Madrid, Cátedra. 1994.
} 
En estos versos se alude a dos causas de los sueños que pueden resultar particularmente interesantes para la relación literatura, psicologia, psiquiatría: el sueño como recreación de las preocupaciones cotidianas y el sueño en relación con el desequilibrio humoral. Podria considerarse gratuita la hipótesis de una posible relación entre los versos de Cervantes y las teorias freudianas si no fuera porque existen numerosas pruebas del fervor que Freud sintió por las obras de Cervantes, con especial atención al Quijote y al Coloquio de los perrosí.

Cabe recordar también otro pasaje cervantino en donde se afirma que los sueños «proceden, o de muchos manjares que suben vapores al cerebro, con que turban el sentido comün, o ya de aquello que el hombre trata más de dian. Una importancia axial tendrá el motivo del sueño en el Quijote, no tanto ya asociado a las numerosas alucinaciones que posee el personaje sino en cuanto que elemento esencial en el capítulo de la Cueva de Montesinos ${ }^{8}$. Este tipo de sueño, que recuerda los avatares cotidianos, luunde sus raices en el insomnium, una de las cinco clases de sueños que existen según Macrobio en cl comentario del Somnium Scipionis ciceroniano".

"Véase el trabajo de León Grinberg y Juan Francisco Rodriguez aCervantes as Cultural Ancestor of Freudw incluido en Quixotic Desire. Psychoanalitic Perpectives on Cervantes, eds. Ruth El Saffar y Diana de Armas Wilson, Ithaca and London Cornwel University Press, 1993, págs. 23-33. Ahí se muestra cómo Freud se dedicó en el verano de 1883 a leer el Quijote que produjo en él una vivida impresión. Hasta tal punto es asi que llega a identificarse con el loco protagonista porque, al igual que él, anda escindido entre su fantasin y la realidad, entre su interés por la psicopatología y sus investigaciones sobre la anatomia del cerebro: "The similarity of thought between Cervantes and Freud now becomes clear. Freud was going to do in the scientilic world what he found Cervantes doing in the literary onem (Ibid., paig. 28). También estos autores hacen referencia a las similitudes existentes entre la relación de Cipión y Berganza, protagonistas del Coloquio de los perros, y la que tiene lugar entre médico y paciente en el psicoanálisis. No extraña, pues, que Freud tomase el nombre de Cipjón mientras que su amigo Silberstein hacia Jo propio Jlamándose Berganza: «Although Cipión does not interpret the facts, he listens. and maintains an attitude of guidance and encouragement perfectly in keeping with the character and personality of Freud. (...) Cipion's attitude in the eCol]oquys is similar to one that the apre-psychoanalyst» Freud would adopt with his patients in his Sladies on Hysteria" (ibid, pejg. 31). Sobre este aspecto, tambien ha de verse el trabajo de E. C. Riley, "Cipion" wirtes to 'Berganza' in the Freudian Academia Española», en Cervantes, XIV,1 (19)4), prigs. 3-18.

${ }^{7}$ Miguel de Cervantes, Los trabajos de Persiles y Sigismunda, ed. Juan Bautista Avalle-Arce, Madrid, Castalia, 1984, págs. 136-137.

B «No hay que olvidar que en todo momento estamos hablando de don Qujjote en sucños. Vale decir, que hablamos de don Qujjote visto por dentro, don Quijote visto por don Quijote, y por nadie más. Por un momento se nos ha permitjdo la extraordinaria experiencia de ver la intimidad esencial del hidalgo manchego, en forma imposible de apreciar para sus compañeros o contrincantes. Tenemos ante nuestros ojos, y al descubierto, las verdaderas raices vitales de ese hombre que se hace llamar don Quijote de la Mancha." J.B. Avalle-Arce y E. C. Riley, "Don Qujjoten en Suma cervantina, Londres, Tamesis Books, 1973, pp. 47-79. La cita se encuentra en la pág. 58.

${ }^{9}$ Asi lo hace ver Aurora Egido, «La cueva de Montesinos y la tradición erasmista 
No sólo la literatura se ha preocupado por ciertos temas, como el sueño o la melancolía, que más adelante podrían constituirse como objeto de estudio por parte de la psiquiatría ${ }^{10}$. También se convirtió en un tema casi tópico en la literatura los efectos devastadores del amor entendido como enfermedad que afecta el normal funcionamiento de la capacidad intelectiva". Todo esto sin mencionar el encumbramiento literario que en tiempos

de ultratumbam, en Cervantes y las pucrtas del sueño. Estudios sobre "La Galatea», el "Quijote» $y$ aEl Persiles», Barcelona, P.P.U., 1994, págs. 137-178 (págs. 149 y s5.)

to Tampoco resulta nuevo el hecho de que el pocta esté afectado por alguna anomalía psicopatológica. Resultan jugosas las anécdotas que relata Juan Huarte de San Juan: «De otro lrenético podría también alirmar que, en más de ocho días, jamás habló palabra que no le buscase luego su consonante, y las más de las veces hacia una copla redondilla muy bien formada. Y espantados los circunstantes de oir hablar en verso a un hombre que en sanidad jamás lo supo hacer, dije que raras veces acontescia ser poeta en la frenesia el que lo era en sanjdad; porque el temperamento que el celebro tiene, estando el hombre sano, con el cual es poeta, ordinariamente se ha de desbaratar en la enlermedad y hacer obras contrariasm Examen de ingenios, ed. Guillermo Serés, Madrid. Cátedra, 1989, püg. 306. Éste y otros fragmentos contribuyeron no poco a la forja de personajes como don Quijote o el licenciado Vidriera. Las eruditas notas de Serés dan cumplida cuenta de la biliografía sobre la influencia de Huarte de Stw Juan en Cervantes así como en los tratados de poética de Carvallo, Pinciano o Cascales. Véanse también las páginas que al asunto le dedica Serés en su introducción (peigs. 62-69). Es necesario advertir que estos procesos maníacos son puestos en relación con el término melancolía: «Y es que sj el hombre cac en alguna en [ermednd por lą cual e] celebro de repente muda su temperatura (como es la manía, melancolía y frenesia) en un momento acontesce perder, si es prudente, cuanto sabe, y dice mil disparates; y si es necio, adquiere más ingenio y habilidad que antes tenías (Ibid. . paigs. 304-305), Indudablemente la conside. ración de Huarte de San Juan, ausente en la obra de Javier Alvarez, le hubiera ayudado a contextualizar de forma más precisa el tratamiento del problema, sobre todo estoy pensando en los capitulos aLa depresión en e] Renacimienton (págs. 126-145) y «Mística y genialidad s (pags. 289-299). Sobre la melancolita en el Quijote puede leerse Agustín Redondo, aLa melancolía y el Quijote de 1605 incluido ahora en Otra manera de leer el Quijote, Madrid, Castalia, 1997, púgs. 121-146. Sobre la depresión en Cervantes existe un trabajo de José Manuel Bailón Blaneas uUn modelo de depresión neurótica en la obra de Cervantes, en Actas del / Congreso Internacional de la Asociación de Cervantistas (II. CINDACINápoles, 4/9 abril 1994/, ed. G. Grilli, Nápoles, Istituto Universitario Orientale. 1995. Annali Istituto Orientale Napolitano, Sezione Romanza, XXXVII, 2 (1995), págs. $463-486$.

"Paolo d Tngisa en su De re medica libri septem considera la enlermedad amorosa como algo similar a la melancolía. En palabras de Massimo Ciavolella en su fundamental libro La malaltia d'amore dellAntichilà al Medioveo, Roma Bulzoni Editore, 1976, "LEngineta considera la malattia damore una malattia di carattere mentale, una passione dell'anima occasionata da uno stato di violenta emozione della ragione (cura): altivitù mentale e amore sono ormai strettamente legati, e poiché il troppo pensare è anche all origine della malinconia, amore e malenconia vengono tacitamento ad assumere connotazioni similiw (pág. 52). Por su partc, Avicena cree que el amor no nace como enfermedad, pero si el pensamiento es muy insistente puede adquirir categoria de enfermedad. El amor hereos mereció la atención de un tratado por primera 
del Renacimiento y del Barroco sufre el tipo del loco que se desarrolla bajo los auspicios de la autoridad que suponen los escritos de Erasmo ${ }^{12}$.

Javier Álvarez viene a recoger todas estas inquietudes que la literatura manifestó desde antiguo en un planteamiento que estí presidido desde sus primeras paiginas por una voluntad decidida de interdisciplinariedad. Su hipótesis de trabajo es sumamente sugestiva y pasa por relacionar la anoche pasivas de San Juan con la depresión endógena que, frente a las depresiones reactivas. se caracteriza por no estar causada por motivos exteriores al propio individuo. Desde este punto de vista puede verse cómo San Juan de la Cruz está desnudando sus abismos en el propio proceso de escritura.

No obstante. y a pesar de lo atractivo de la hipótesis, quizás no se plantea con el detenimiento necesario la cuestión del status de los textos analizados. No es lo mismo sacar conclusiones de este tipo de un texto lírico, que de un texto en prosa que acompaña a su obra lírica y actúa como comentario de ésta, que de una carta intima. Si de éste último pueden inferirse una serie de conclusiones que, efectivamente, reviertan sobre la caracterización anímica de San Juan ${ }^{13}$, en los otros dos casos hay que contar con otros factores que indudablemente habrín de distorsionar la sinceridad del mensaje.

Dentro de la poesía lírica en modo alguno puede defenderse, hay que recordar que estamos en el XVI, una poesín de tipo confesional, idea ésta persistente en los acercamientos al estudio de la lírica pero que posee una raigambre eminentemente romántica ${ }^{14}$. Incluso en los casos más carismáticos,

vez en la obra del médico valenciuno del siglo XIII: Arnaldo Vilanova: De amore qui heroicus nominatur (Jbid, píg. 68). Muestras de un excelente estudio sobre el tema y su repercusión en la literatura áurea, como no podía ser de otra manera, son las páginas de Aurora Egido: aLa enfermedad de amor en el aDesengañom incluidas en Silva de Andalucia (Estudios sobre poesia barroca), Málaga, Diputaciōn de Málaga, 1990, (pägs. 111-141) en donde no falta la necesaria alusión a Huarte de San Juan, y «El Persiles y la enfermedad de amor", en Cervantes y las puerias del sueño. op. cil., págs. 251-284 en donde se ofrece un caudal bibliográfico ingente.

12 Puede consultarse la obra Folie et déraisson à la Renaissance. Université de Bruxelles, 1976. Son interesantes los numerosos trabajos de Francisco Márquez Villanueva que dedica a la literatura del Joco, sobre todo en relación con la obra de Cervantes, y Antonio Vilanova. Imprescindibles son los de Francisco Márquez Villanueva «El caballero dol verde Gabén y su reino de la paradoja” en Personajes y temas del Quijote, Madrid, Taurus, 1975, págs. 147-227 y los diferentes trabajos agrupados ahora en el volumen Trabajos y días cervantinos, Alcalá de Henares, Centro de Estudios Cervantinos, 1995; véase también su artículo «Planteamiento de la literatura del «loco" en Españas, en Sin Nombre, 10 (1980), pígs. 7-25. De Antonio Vilanova el volumen Erasmo y Cervantes, Barcelona, Lumen, 1989.

${ }^{13}$ Léase Claudio Guillén, «Al borde de la literariedad: literatura y epistolaridad», en Tropelías, 2 (1991), págs. 71-92.

${ }^{14}$ No obstante, existen precedentes en la interpretación more biographico de la obra lírica. Véase para las interpretaciones del Canzoniere de Petrarca, Luigi Baldacci. El petrarchismo nel Cinquecento. Padova, Liviana Editrice, 1974, especialmente el capítulo: «il Petrarca specchio di vita» (pågs. 49-74). En ello innluye tambiến el hallazgo 
como el de Lope, no resulta fructifero pensar en una poesia de corte autobiográlico ${ }^{15}$. Indudable es el hecho de que el autor real construye un personaje que se erige en protagonista de la enunciación lírica. En casos como Petrarca, ese personaje podría -aunque no tiene por qué- coincidir en mayor o nenor medida con el propio Petrarca, pero en la evolución ulterior de la estética petrarquista la estructura del cancionero (construido sobre la introspección y la averiguación sentimental de un "yo" lírico muy homogéneo) acabn por quebrarse. La poesía, bajo la horma del Manierismo, acaba por delinirse como actividad artística. El speculum vilae del Canzoniere se transforma en una concepción de la poesia como destreza. Ese yo lírico comienza a fragmentarse como consecuencia de la introducción de un mayor pluritematismo dentro del seno de los cancioneros petrarquistas. Por otra parte, la introducción de la bucólica en el Cancionero petrarquista, ejemplos pueden ser Garcilaso en el Renacimiento o Soto de Rojas en el Barroco, facilita la descentralización de la experiencia lírica que pasa del "yo" a la dramatización del proceso afectivo, ahora puesto en boca de pastores. Tambiẻn en la evolución de la lírica petrarquista se van creando "máscaras" que de una forma explícita filtran la voz del poeta. La poesía burlesca, por ejemplo, especializa un determindo locutor que dista mucho de poder identilicarse con el autor real. Por todo ello es necesaria una determinada cautela a la hora de examinar la lírica como fuente biográlical".

Para el caso de los comentarios que acompañan al texto lírico hay que señalar las conexiones que tal práctica tiene con la exégesis medieval del texto lírico propugnada sobre todo por Dante y Albertino Mussato. Ambos defendían,

del «yo» lírito como mecanismo de cohesión textual que crea un personaje fácilmente identificable con el poeta real. Para ello. Marco Santagata. Dal sonetto al Canzoniere. Hicerche sulla preistoria e la costituzioni di un genere, Padova, Liviana Editrice, $1989\left(2^{2}\right.$ ed.), el capítulo «Rerum vulgarium fragmenta: L'înizio della storia», págs. 155-176. El caso de Garcilaso también es paradigmaitico: la unión vidaliteratura es casi una constante en los estudios sobre su lírica. Así lo indica Luis Iglesias Feijoo en un estudio sobre la égloga I «Lectura de la égloga I», en Academia literaria renacentista IV. Garcilaso, (1986), Salamanca, Universidad de Salamanca, págs. 61-82.

15. Vêase Yolanda Novo, «《Erlebnis» y «Poesis» en la poesia de Lope de Vega. El ciclo del arrepentimiento y las Rimas Sacras (1614)m, en Boletín de la Biblioteca Menendez Pelayo, LXVII (1991), págs. 35-74. Para la concepción de la poesía como ficción, José Maria Pozuelo Yvancos, "Lirica e linzione (in margine a Ch. Batteux)m, en Strumenti critici, 6:1, $\mathrm{n}^{\circ} 65$ (1991), pågs. 63-93.

16 Sobre este interesante asunto, véanse a modo de botón de muestra los trabajos de Antonio Carreira, "El ayo» de Góngora: sus máscaras y epifanias", en Compäs de Letras, 1 (1992), págs. 197-220 y Antonio Pérez Lasheras, «De máscaras y amores (la superación del petrarquismo en las primeras composiciones gongorinas), en Tropelías, 2 (1991), págs. 129-143. De las distintas máscaras en Lope se han ocupado Yolanda Novo, Las «Rimas Sacras» de Lope de Vega: Disposicion y sentido. Santiago, Universidad de Santiago, 1990, págs. 261-302, y Antonio Carreño, «Los mitos del yo lírico: Rimas (1609) de Lope de Vega», en Edad de Oro, XIV (1995), págs. 55-72 que remite a otros trabajos suyos sobre el asunto. 
frente a la práctica condenatoria de la escolástica más rancia, la licitud de varios niveles interpretativos para la lírica, hecho éste que sólo hasta entonces habia sido reservado para las Sagradas Escrituras ${ }^{17}$. Incluso Petrarca, cuyo legado lírico del Canzoniere había descubierto el molde artístico y sentimental que tanto influyó en el frenacimiento, se muestra en su obra pastoril totalmente medievalizante al concebirla desde un prisma alegórico ${ }^{13}$. Se trata de una decodilicación dirigida por el propio autor. No ha lugar para la ambigüedad y en este sentido podrian explicarse los comentarios de San Juan". El Cántico espiritual es un poema de una sensualidad arrebatadora que sólo en conjunción con la propia exégesis en prosa de San Juan, exégesis -por cierto- que puede tildarse de una interpretación aberrante llevada a cabo por el propio autor- puede interpretarse desde un prisma religioso ${ }^{20}$. El propósito es eminentemente didáctico a la par que desarrolla una coartada perfecta para evitar cualquier suspicacia eclesiástica.

AJgunas de estas precauciones las intuye el autor y acaba por recogerlas en el transcurso del libro en un pärrafo de especial importancia desde el punto de vistu melodológico:

Podria argumentarse que el contenido depresivo que se advierte en las obras de san Juan de la Cruz, a pesar de la extensión y detalle con que lo relata. podría no ser original suyo sino copiado de otros autores que le precedieron (...)

Seguin eslo se podria razonar que estas descripciones de la depresión no le

${ }^{17}$ Ernst Robert Curtius, Literatura europea y Edad Media latina, México. Fondo de Cultura Económica, 1984, vol l, páigs. 305-314.

${ }^{18}$ Véase. José Dominguez Caparrós, Origenes del discurso crítico. Teorias antiguas y medievales sobre la interpretación Madrid, Gredos, 1993, paigs. 174-216. También la Iraducción de la Carta X,4 de Le familiari de Petrarea, que constituye un buen ejemplo sobre la interpretación alegórica de una de sus bucólicas, págs. 221-230. Sobre la concepción del poeta por parte de Dante pueden servir como inicio las päginas de Umberto Eco, Arte y belleza en la estética medieval, Barcelona, Lumen, 1997, en especial el capítulo «Dante y la nueva concepción del poeta», páżs. 152-159, en donde se examina la problemática autoria de la Epístola XIII a la luz de sus semejanzas y diferencias con la doctrina desarrollada en el Convivio. En ambos lugares se defjende para la poesía varios niveles de interpretación. Esto lo lleva a la práctica en cierto modo San Juan, quien realiza una interpretación alegórica de! texto lírico. También sobre la Epistola XIII de Dante, Umberto Eco, "La epistola XIt1, el alegorismo medieval, el simbolismo moderno", en De los espejos y otros ensayos, Barcelona, Lumen, 1988, págs. 231-259.

"Tampeco ha de olvidarse el ejemplo de Dante y su Vita Nuova.

${ }^{20}$ Sobre el problema de la exégesis en San Juan de la Cruz puede leerse Emilio Lledó, «Notas hermenéuticas sobre un lenguaje que se habla a si mismo", en Herméneutica y mistica: San Juan de la Cruz, eds. Jose Angel Valente y José Lara Garrido, Madrid, Tecлos, 1995, págs. 99-122; y también Nadine Ly, «La poética de los comentarios (algunos rasgos lingüísticos) en el mismo volumen, págs. 221-245. Para una visión de la exégisis bíhlica en el XVI, Karl Kölz, "Exégesis bíblica y erudiciớn lijológica en el humanismo español", en Fray Luis de León. Historia, Humanismo y Letras, eds. Víctor García de la Concha y Javier San José Lera, Salamanca, Universidad de Salamanca, pígs. 145-158. 
pertenecen en origen, sino que las habia tomado prestadas de otros precursores. Pues bien, aun sirviéndonos únicamente del contenido de sus obras, esta hipótesis parece poco verosímil. y ello por dos razones: en primer lugar, porque, como hemos señalado repetidas veces, la descripción que hace san Juan es más extensa y rica que ninguna de las ya precedentes y en ella aparecen detalles de enorme finura psicopatológica que suponen un grado de conocimiento de la depresion que no aparece en los otros autores.

Pero es que hay además otro importante argumento que nos hace pensar que san Juan de la Cruz habla de su propia experiencia. Efectivamente. él mismo asegura que el análisis de la noche pasiva del alma sólo puede llevarlo a cabo quien ha pasado por ello y la ha superados (pág. 164)

Hay en esta cita una apuesta por la propia vivencia en detrimento de la tradición. Sucede que aquí se hace explícito el porquẻ de esa elección. En todo caso, subsiste lo problemático del enfrentamiento entre dos concepciones del hecho literario: como cauce de lo afectivo frente a la concepción como actividad artística guiada por las convenciones que marca la propia tradición literaria.

Quizás dentro de la contextualización literaria que me guía podria hacerse referencia a algunas ausencias bibliográficas que, por lo relevante, no dejan de ser necesarias en los estudios de San Juan. En este sentido se podría aludir a la do la obra ya citada de José Angel Valente y José Lara Garrido, asi como las aportaciones que sobre el tema de la noche, desarrollado por Javier Alvarez en las páginas 89-96, han hecho tanto Domingo Yndurain como $\mathrm{M}^{\mathrm{n}}$ Jesús Mancho Duque, si bien es cierto que ésta última aparece convenientemente recogida en In bibliografia ${ }^{21}$. Todos estos son trabajos que analizan el fenómeno desde un punto de vista que tiene en cuenta la tradición literaria. Se comprende que el esfuerzo de estar trabajando en un doble frente conlleva necesariamente algunas ausencias que hubieran redondeado el trabajo desarrollado por Javier Álvarez. En lo referente al período unitivo, que se estudia en las páginas 9799. hay que decir que inevitablemente remite al tópico del anima animat ubi amal, que ha sido estudiado recientemente de forma espléndida por Guillermo Serés ${ }^{22}$. En este sentido hubiera ayudado al autor a enmarcar desde el punto de vista de la tradición literaria y filosófica uno de los momentos cruciales del poema de la "Noche oscura del alma".

Javier Álvarez se muestra valiente en la interpretación de los rasgos

${ }^{21} \mathrm{M}^{2}$ Jesús Mancho Duque, Palabras y símbolos en San Juan de la Cruz, Madrid. Fundación Universitaria Española y Universidad Pontificia de Salamanca, 1993. Los capítulos que interasan sobre todo son «Panorámica sobre las raices originarias del símbolo de la «nochen de San Juan de la Cruz" (págs. 177-209), que habfa sido publicado con anterioridad en Doletín de la Bibliteca Menéndez Pelayo, LXIII (1987), pags. 125155, y «El símbolo de la noche: ejes semúnticos» (págs. 211-232). Domingo Yndurain, Aproximación a San Juan de la Cruz, Madrid, Cátedra, 1990, especialmente el capítulo «Luz y tinieblas. La noche» (págs. 173-207).

${ }^{22}$ La transformación de los amantes, Barcelona, Crítica, 1996, quien, por cierto dedica unas jugosas páginas al símbolo de la noche en la obra de San Juan (págs. 259 y s5.). Se apunta una extensa bibliografia en la nota 9 de la pág. 267. 
estilísticos de San Juan que se desarrollan en las páginas 185-193. Muchas de las peculiaridades son explicadas en función de la personalidad obsesiva de San Juan: «Pero la personalidad obsesiva del místico se desprende claramente no sólo del contenido de su vida y de su doctrina, sino también de la forma de escribir y del modo de organizar y estructurar las distintas partes de sus escritos." (pág. 185). Quizás las posibles objeciones que desde el ámbito literario se pudieran hacer a asertos como el precedente son previstos por el autor cuando afirma: «Esta tendencia obsesiva de san Juan de la Cruz a insistir una y otra vez en el mismo lexema o en igual construcción sintagmática se traduce en muchas ocasiones en construcciones llenas de belleza, ritmo y cadencia que se aproximan al lenguaje poéticon (pig. 190). En este caso Javier Alvarez atina una vez más; sin embargo, personalmente prefiero entender el fenómeno al revés: la tradición retórica, tua vez desvinculada del ámbito jurídico, pronto codilicó las normas de cómo se debían escribir los textos literarios y las figuras de repetición, no cabe duda, lueron contempladas como recursos indispensables en el ornatus. Dentro del ámbito del formalismo, Jakobson caracterizó el lenguaje poético en función de las repeticiones que operaban en el ámbito sintagmático y en esa línea se sitúan también los apareamientos de Samuel Levin ${ }^{23}$. También la circunstancia literaria que preside la obra de San Juan ha de ponerse en relación con la poética del Manierismo que transformó el legado petraquista. Por una parte el Manierismo descompuso el paradigma petrarquista al seleccionar unos determinados temas y saturarlos mediante un uso repetitivo, consecuencia del intelectualismo del propio proceso poético ${ }^{24}$. Que estos estilemas lleguen a darse en una frecuencia tan alta que pueda sacarse alguna conclusión sobre el carácter patológico que representa la depresión endógena propiciada por una personalidad obsesiva puede ser una perspectiva válida, pero el razonamiento, a parte de ser cauto, habrá de tomar en consideración primero el aspecto retórico y luego la motivación vital.

La preponderancia que se le da al factor vital obliga a tomas de posición por parte del autor que tícne matices rayanos a una concepción del poeta romántico. Así sucedo en la página 236 en donde se asocia el estado mental patológico a la creación artística ${ }^{25}$. Esto impele a poner en relación la

${ }^{23}$ Estrucuturas lingüisticas en la poesia. Madrid, Cátedra, 1990, 5 edición.

${ }^{24}$ A este respecto comenta Emilio Orozco: uen la lirica de lines del siglo XVI se intensilican los artificios de correlación de poemas y plurimembración de versos; esto es. La fijación de unos cauces rígidos por entre los cuales ha de fluir retenidamente el pensamiento poético; ello no es lo mismo que la libre y complicada construcción sintáctica impuesta desde dentro como una necesiad expresiva de la más intima agitación del poetam, Manierismo y Barroco, Madrid, Cátedra, 1988. pág. 43. Véase, por ejemplo. Amadeo Quondam. La parola nel labirinto. Società e scrittura del Manierismo a Napoli, Bari, Laterza, 1975.

${ }^{25}$ Quizás en el afán de atar todos los cabos algunas afirmaciones resulten un tanto impulsivas, comprensible ello por lo que de pionero plantea su tesis: aA partir de nuestro trabajo podemos asegurar con una alta probabilidad de certeza que todos estos 
personalidad obsesiva de San Juan con el hecho de que exitan varias redacciones de sus obras y de que algunas de ellas no se hayan finalizado. Esta hipótesis no deja de ser arriesgada ya que la historia de la literatura se halla jalonada de casos de múltiples redacciones que plantean problemas de difícil resolución; pueden traerse a colación casos como los del Arcipreste de Hita, pasando por Herrera y llegando incluso a Lorca, escritor muy proclive a forjar proyectos que no cristalizaban necesariamente en un libro. A este respecto resulta paradigmático el libro de Tierra y luna que se integró posteriormente en Poeta en Nueva York o el caso de determinados poemas como "La Casida de las palomas oscuras", poema que formó parte de varios poemarios hasta alojarse definitivamente en el Divón del Tamaril, eso sin mencionar los problemas textuales que amenazaron El Público o el misterio que envuelve Los sonetos del amor oscuro. Con ello se deduce que es bastante frecuente la insatisfacción en el escritor: tal insatisfacción le lleva a reescribir y corregir su obra. a abandonar proyectos, a forjar otros nuevos que no se sabe si se consolidarán. El mismo Juan Ramón dedicó toda su vida a la realización de su proyecto poético: su dios deseado y deseante. En ese sentido se puede observar cómo cada escritor puede estar más o menos acechado por la sombra de la obsesión por su obra. Resta calibrar en qué supuestos esa obsesión propia del creador desarrolla una patología perfectamente delimitable desde el terreno de la psiquiatria ${ }^{26}$.

También se atribuye a este carícter melancólico de San Juan el hecho de que gran parte de su correspondencia haya desaparecido. La causa, según J. Alvarez, puede ser el hecho de que en esa correspondencia se viese claramente la dolencia de San Juan y ello en torpeceria, de haberse conocido, el proceso de beatificación.

Otra hipútesis que se lanza en el libro resulta ciertamente rebuscada. Se viene a conjeturar posibles antecedentes do suicidio en la familia de San Juan por vía materna. Se señala que no se ha de perder de vista el carácter hereditario consustancial a ciertos tipos de depresión: se explicaría asi el porqué de la depresión en San Juan. Sin embargo, no existe ninguna prueba documental que apoye esta idea. En este caso se llega mís que a una

aspectos enigmíticos de la vida y de la obra de san Juan de la Cruz quedarán suficientemente aclarados: la personalidad obsesiva del santo y las depresiones endógenas a ella asociadas constituirán la clave que falta en el rompecabezas, la pieza multidentada que posibjlitaría engranar y explicar todos los componentes del enigma.» (pág. 262).

27 En este sentido la opción que toma J. Álvarez resulta clara: «Atenjéndonos, pues, a nuestra hipútesis -la personalidad melancólica de san Juan de la Cruz y las depresiones a ella asociadas- resulta fácil explicar otro de los grandes enigmas de la biogralía de fray Juan de la Cruz: el porqué de la no finalización de alguna de sus obras y el porqué de un final de tan baja calidad como el que se nos ofrece en Subida del Monte Carmelon (pág. 270).

${ }^{27}$ Lector in fabula. La cooperación interpretativa en el texto narrativo, Barcelona, Lumen, 1987 (2"ed.), págs. 85-87. 
interpretación a un uso del texto, por utilizar dos conceptos estudiados por Umberto $\mathrm{Eco}^{27}$. Conectado con esta idea se cita un fragmento del comentario al Cántico espiritual en que se hace alusión al color moreno que, a través del testimonio de Alonso de Freylas (1601), se pone en relación con la melancolía. Quizás pudiera interpretarse más fácilmente el texto si nos atenemos a la tradición lírica castellana y sus villancicos en cuyo inventario reza el tema de la morena ${ }^{28}$. Que luego quiera el propio San Juan interpretarlo de una forma determinada que lo desvincula de la tradición poética y lo examina desde un prisma forzadamente religioso eso se inscribe en una práctica exégetica que, como se ha indicado, se inicia ya en la Edad Media. Podría argumentarse que San Juan oficia en sus comentarios como un intérprete más, si bien privilegiado, de su su propio texto, pero ha de recordarse que su poesia puede ser estudiada, rescatando la expresión de Dámaso Alonso, desde esta ladera. Incluso podría llegar a argumentarse que una interpretación de la poesía de San Juan atendiendo sólo y exclusivamente a la tradición lírica resulta menos aberrante que la que proporciona su propio autor por cuanto que supone la exégesis de San Juan un sistema hermenéutico que se vale de elementos extratextuales.

Puede afirmarse, concluyendo, que el libro constituye un notable esluerzo por conciliar disciplinas dispares. En lo sugestivo y arriesgado de sus hipótesis puede cifrarse su seña de identidad. Algunos aspectos, qué duda cabe, podrian resultar discutibles y en estas líneas se ha intentado esbozar algunos reparos al abrigo de la teoria de la literatura y una contextualización literaria de un problema de tan dilícil resolución como son las relaciones autor/texto. Dilícil resulta internarse en el laberinto del dolor en el que el dudoso hilo de Ariadna está formado por los escritos que a modo de brasa recuerdan cuánto de incendio hubo. Javier Álvarez ha elegido profundizar en la mística desde un ángulo inusual y trazar sendas siempre resulta gratificante para quien transita detrás. Esta obra espera el juicio atento de especialistas en psiquiatria, capaces de aquilatar los logros que a mis ojos sin duda alguna

28 Antonio Sánchez Romeralo, El villancico, Madrid, Gredos, 1969, págs. 56-59. Por supuesto también hay que pensar en el «nigra sunt, sed formosa, filiac lerusalem» del Cantar de los Cantares. Véase Terence O Reilly, "El Cántico espiritual y la interpretación mística del Canlar de los cantaresw en Hermenéulica y mistica... op. cit. págs. 271 . 280. No hay que olvidar que en este punto San Juan interpreta alegóricamente el Cantar de los Cantares. Ën los albores del XVII, Luis Alfonso de Carvallo todavía concebia una visión alegórica de la égloga, Véase El cisne de Apolo, ed. Alberto Porqueras Mayo. Madrid, CSIC, 1958, vol II, págs. 103-104. Para la consideración de la égloga en el Siglo de Oro el importante estudio de Aurora Egido, «Sin poética hay poetas. Sobre la teoría de la égloga en cl Siglo de Orom en Criticón 30 (1985), págs. 43-77. Las posibles relaciones del Cántico con el género bucólico son examinadas por Cristóbal Cuevas en su introduc. ción a San Juan de la Cruz. Cántico espiritual. Poesías, Madrid, Alhambra, 1979, págs. 40-48. La relación entre El Cántico espiritual y la Diana de Montemayor es examinada tambièn por Juan Montero, «De la Diana de Montemayor al Cántico espiritual: especulaciones en Ja luentem, en Edad de Oro. XI (1992), págs. 113-121. 
han pasado desapercibidos por ignorancia propia. Queda, al final, la balanza en difícil equilibrio: de un lado la confesionalidad de los textos; de otro, su ficcionalidad que tamiza la propia vivencia desde una perspectiva literaria. En la medida en que el lector se incline por uno u otro este libro habra de llevarlo a disentir de sus planteamientos o a la aventura de emboscarse en los vericuetos del místico, pero nunca al desierto de la indiferencia. 